\title{
Dissecting molecular interactions involved in recognition of target disulfides by the barley thioredoxin system
}

Björnberg, Olof; Maeda, Kenji; Svensson, Birte; Hägglund, Per

Published in:
Biochemistry

Link to article, DOI:

10.1021/bi301051b

Publication date:

2012

Document Version

Publisher's PDF, also known as Version of record

Link back to DTU Orbit

Citation (APA):

Björnberg, O., Maeda, K., Svensson, B., \& Hägglund, P. (2012). Dissecting molecular interactions involved in recognition of target disulfides by the barley thioredoxin system. Biochemistry, 51(49), 9930-9939.

https://doi.org/10.1021/bi301051b

\section{General rights}

Copyright and moral rights for the publications made accessible in the public portal are retained by the authors and/or other copyright owners and it is a condition of accessing publications that users recognise and abide by the legal requirements associated with these rights.

- Users may download and print one copy of any publication from the public portal for the purpose of private study or research.

- You may not further distribute the material or use it for any profit-making activity or commercial gain

- You may freely distribute the URL identifying the publication in the public portal 


\title{
Dissecting Molecular Interactions Involved in Recognition of Target Disulfides by the Barley Thioredoxin System
}

\author{
Olof Björnberg, Kenji Maeda, ${ }^{\dagger}$ Birte Svensson, and Per Hägglund* \\ Enzyme and Protein Chemistry, Department of Systems Biology, Søltofts Plads, Building 224, Technical University of Denmark, \\ DK-2800 Kgs. Lyngby, Denmark
}

\section{Supporting Information}

ABSTRACT: Thioredoxin reduces disulfide bonds, thus regulating activities of target proteins in various biological systems, e.g., inactivation of inhibitors of starch hydrolases and proteases in germinating plant seeds. In the three-dimensional structure of a complex with barley $\alpha$-amylase/subtilisin inhibitor (BASI), two loops in barley thioredoxin h2 (HvTrxh2), containing an invariant cis-proline $\left({ }^{86} \mathrm{EAMP}^{89}\right)$ and a conserved glycine $\left({ }^{104} \mathrm{VGA}^{106}\right)$, surround the active site cysteines $\left({ }^{45} \mathrm{WCGPC}^{49}\right)$ and contribute to binding of BASI through backbone-backbone hydrogen bonds [Maeda, K., Hägglund, P., Finnie, C., Svensson, B., and Henriksen, A. (2006) Structure 14, 1701-1710]. This study involves mutational analysis of key amino acid residues from these two loops in reactions with three protein disulfide

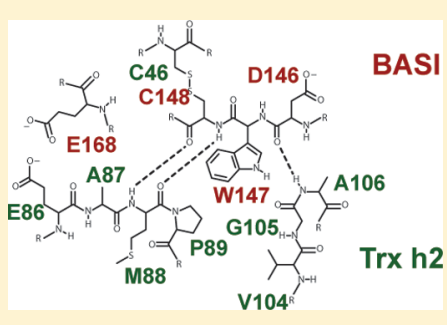
substrates, BASI, barley glutathione peroxidase, and bovine insulin as well as with NADPH-dependent barley thioredoxin reductase. HvTrxh2 M88G and M88A adjacent to the invariant cis-proline lost efficiency in both BASI disulfide reduction and recycling by thioredoxin reductase. These effects were further pronounced in M88P lacking a backbone NH group. Remarkably, HvTrxh2 E86R in the same loop displayed overall retained catalytic properties, with the exception of a 3-fold increased activity toward BASI. From the ${ }^{104} \mathrm{VGA}^{106}$ loop, a backbone hydrogen bond donated by A106 appears to be important for target disulfide recognition as A106P lost $90 \%$ activity toward BASI but was efficiently recycled by thioredoxin reductase. The findings support important roles in target recognition of backbone-backbone hydrogen bond and electrostatic interactions and are discussed in relation to earlier structural and functional studies of thioredoxins and related proteins.

$\mathrm{T}$ hioredoxin $(\mathrm{Trx})$ is a small, ubiquitous, and stable protein with a redox active dithiol/disulfide motif (WC[G/ P]PC). Trx reduces catalytic disulfide bonds in enzymes like ribonucleotide reductase and peroxiredoxins but also modulates activities of other target proteins by reducing noncatalytic disulfides. ${ }^{1}$ In the cytoplasm, oxidized Trx is recycled to the catalytically active dithiol form by the dimeric NADPHdependent thioredoxin reductase (NTR). So-called lowmolecular weight NTRs from bacteria, fungi, and plants (subunit $M_{\mathrm{r}}$ of $\sim 35 \mathrm{kDa}$ ) are distantly related to vertebrate NTRs (subunit $M_{\mathrm{r}}$ of $\sim 55 \mathrm{kDa}$ ), which contain a C-terminal selenocysteine redox center. ${ }^{1}$ Reducing equivalents are transferred from NADPH via NTR-bound FAD and a pair of redox active cysteine residues, which following a major conformational change reduces the active site disulfide of oxidized Trx. ${ }^{2,3}$ Thus, Trx possesses an active site surface region adapted for molecular interactions with both NTR and various target proteins. Available structures of NTR-Trx and Trx-target protein complexes provide insight into features important for protein-protein recognition, but a thorough understanding of key structural determinants in Trx and the mode of action lags behind. $^{3-10}$

Plants possess Trx isozymes of remarkable variety with diverse subcellular locations, and more than 400 putative target proteins have been identified. ${ }^{11}$ The h-type Trx is commonly found in the cytosol, and in cereal seeds, it is proposed to act as a germination "wake up signal" by reducing and thus facilitating the mobilization of storage proteins and by inactivating inhibitors of enzymes that hydrolyze starch and proteins. ${ }^{12-14}$ We previously identified numerous potential target proteins of barley seed thioredoxins (HvTrxh1 and HvTrxh2), which included the bifunctional $\alpha$-amylase/subtilisin inhibitor (BASI) of the Kunitz-type trypsin inhibitor family. ${ }^{15-19}$ Two conserved structural disulfides, C44-C93 and C144-C148, are located on opposite sides of BASI, and HvTrxh preferentially reduced the C144-C148 disulfide situated at the intermolecular surface of the complex with barley $\alpha$-amylase. ${ }^{16,20}$

The structure of a trapped $\mathrm{C} 46_{\mathrm{HvTrxh} 2}-\mathrm{C} 148_{\mathrm{BASI}}$ disulfidebonded HvTrxh2-BASI complex mimicking the reaction intermediate following the initial nucleophilic attack by HvTrxh2 on the BASI target disulfide revealed a "substrate recognition loop motif" near the intermolecular disulfide bond in a shallow groove formed by three loops structurally conserved in the Trx family (Figure 1 and Table 1). ${ }^{7}$ The backbone amide and carbonyl groups of $\mathrm{C} 148_{\text {BASI }}$ formed antiparallel hydrogen bonds to backbone atoms of $\mathrm{M} 88_{\mathrm{HvTrxh} 2}$ preceding P89 ${ }_{\mathrm{HvT} \text { Trxh } 2}$ that invariantly adopts a cis configuration in a loop between $\alpha 3$ and $\beta 4$ in Trx and related proteins, e.g., glutaredoxin and glutathione transferase. ${ }^{21} \mathrm{M} 88_{\mathrm{HvTrxh} 2}$ is conserved among plant h-type Trx but corresponds to I75 in Escherichia coli Trx1 (EcTrx1) (Table 1). ${ }^{22}$ A third

Received: August 3, 2012

Revised: October 31, 2012

Published: November 19, 2012 


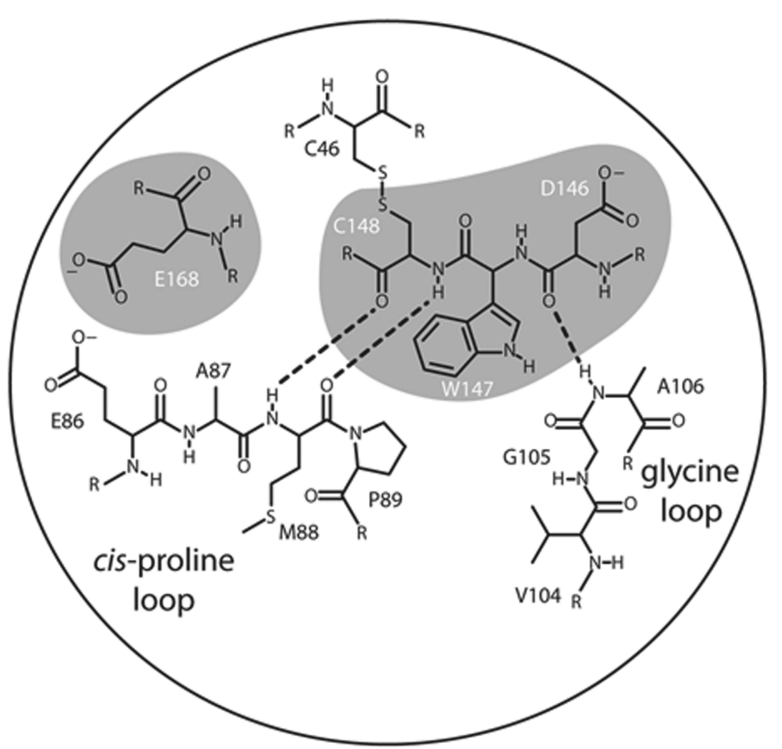

Figure 1. Schematic view of polar contacts between HvTrxh2 and BASI in the structure of the HvTrxh2-BASI complex (PDB entry 2ITW). Selected HvTrxh2 residues are shown with black labels and BASI residues with gray background and white labels. Hydrogen bonds between BASI C148 and HvTrxh2 M88 in the cis-proline loop (E86P89) and between BASI D146 and A106 in the HvTrxh2 glycine loop (V104-A106) are shown as dashed lines. The carboxylic acid groups of BASI E168 and HvTrxh2 E86 are in the proximity of each other (4.6 $\AA$ is the shortest distance between $\mathrm{OE}$ atoms). A threedimensional representation of the three hydrogen bonds in the HvTrxh2-BASI complex is displayed in Figure 3B of ref 7. A corresponding illustration of the EcTrx1-PAPS reductase complex is found in Figure 4 of ref 8.

Table 1. Sequence Alignment of Trxs with Respect to the Substrate Recognition Loop Motif ${ }^{a}$

$\begin{array}{lclll} & \text { PDB } & \mathbf{4 5 - 4 9} & \mathbf{8 6 - 8 9} & \mathbf{1 0 4 - 1 0 6} \\ \text { HVTrxh2 } & \text { 2VLV } & \text { WCGPC } & \text { EAMP } & \text { VGA } \\ \text { HvTrxh1 } & \text { 2VM2 } & ---- & ---- & --\bar{G} \\ \text { AtTrxh1 } & \text { 1XFL } & ---- & \text { Q--- } & --- \\ \text { PtTrxh1 } & \text { 1TI3 } & --P-- & ---- & --- \\ \text { H Trx1 } & 3 \text { TRX } & ---- & \text { KC-- } & \text { S-- } \\ \text { SCTrx1 } & \text { 3F3Q } & ---- & \text { S--- } & --- \\ \text { ECTrx1 } & \text { 1SRX } & ---- & \text { RGI- } & --- \\ & & \mathbf{3 1 - 3 5} & \mathbf{7 3 - 7 6} & \mathbf{9 1 - 9 3}\end{array}$

${ }^{a}$ Seven selected Trxs with known three-dimensional structures were aligned according to the substrate recognition loop motif in HvTrxh2 as defined in the complex with BASI. ${ }^{7}$ The two loops EAMP and VGA are named the cis-proline and glycine loop, respectively, after the invariant residues (italics). Mutagenized residues in HvTrxh2 are underlined, and sequence identities are marked (-) to six other Trxs from Hordeum vulgare (barley) (Hv), Arabidopsis thaliana (At), Populus trichocarpa $(\mathrm{Pt})$, Homo sapiens (Hs), Saccharomyces cerevisiae $(\mathrm{Sc})$, and E. coli $(\mathrm{Ec})$. Residue numbering for HvTrxh2 and EcTrx1 is shown above and below the sequences, respectively.

intermolecular backbone-backbone hydrogen bond is seen between $\mathrm{A} 106_{\mathrm{HvTrxh} 2} \mathrm{NH}$ and D146 $\mathrm{BASI}$ O (Figure 1). A106 follows an invariant glycine residue found in Trxs and glutaredoxins in the loop between $\beta 5$ and $\alpha 4$, here termed the glycine loop (Table 1). A106 is well-conserved among Trxs of diverse origin, although HvTrxh1 noticeably has glycine at this position (Table 1). Hydrogen bonding patterns similar to those of the HvTrxh2-BASI complex are found in disulfidebonded complexes between Trx and short synthetic peptide fragments derived from transcription factors NF- $\kappa \mathrm{B}$ and ref- 1 and with the proteins arsenate reductase and $3^{\prime}$-phosphoadenosine-5'-phosphosulfate (PAPS) reductase. ${ }^{5,6,8,9}$ In the recently determined structure of yeast Trx 2 in complex with methionine sulfoxide reductase, the similarity is striking as three fully analogous antiparallel backbone-backbone hydrogen bonds are found. ${ }^{10}$ The interactions in the HvTrxh2-BASI complex therefore appear to be characteristic of disulfide target recognition by Trxs.

The barley Trx system is here used as a model to study the molecular interactions involved in target disulfide recognition. A comparison of the detailed characteristic of the interactions at the proteins interfaces observed in the structures of the HvTrxh2-BASI complex and EcTrx1 linked to E. coli NTR (EcNTR) and PAPS reductase, respectively (Table 2), motivated the mutational analysis of the functional roles of HvTrxh2 E86, M88, and A106 in reactions with three targets proteins, BASI, barley glutathione peroxidase, and bovine insulin, and with barley NTR (HvNTR2). The importance of backbone hydrogen bonds between Trx and target proteins was probed by mutational elimination of backbone amide hydrogens in HvTrxh2 M88P and A106P. Notably, while the M88P mutant was deficient in all assays performed, A106P showed reduced activity toward BASI and no loss of HvNTR2mediated recycling. Engineering a hypothesized electrostatic attraction between $E 86 \mathrm{R}_{\mathrm{HvTrxh}}$ and $\mathrm{E} 168_{\mathrm{BASI}}$ conferred a remarkable activity increase toward BASI.

\section{EXPERIMENTAL PROCEDURES}

Site-Directed Mutagenesis. HvTrxh2 E86R, M88G, M88A, M88P, M88L, A106G, A106S, A106P, and A106Y were generated using Quikchange (Stratagene) and the HvTrxh2 gene cloned in pET-15b (Novagen), providing an $\mathrm{N}$-terminal His tag and thrombin cleavage site, as a template. For mutagenesis primers, see Table S1 of the Supporting Information. Mutagenesis was confirmed by bidirectional DNA sequencing, and plasmids were transformed into E. coli Rosetta DE3 cells (Novagen) for expression.

Protein Production and Quantification. Wild-type (wt) HvTrxh2 and mutants, BASI, and HvNTR2 were produced as described, purified (His-Trap HP column, GE Healthcare), dialyzed against $30 \mathrm{mM}$ Tris- $\mathrm{HCl}(\mathrm{pH} 8.0)$, concentrated (Amicon Ultra Centrifugal Filter Device, Millipore), and further purified by gel filtration (HiLoad 26/60 Superdex 75 column, GE Healthcare) in $30 \mathrm{mM}$ Tris- $\mathrm{HCl}$ (pH 8.0) and 0.2 $\mathrm{M} \mathrm{NaCl}{ }^{7,23,24}$ Eluted proteins were dialyzed against $30 \mathrm{mM}$ Tris- $\mathrm{HCl}$ ( $\mathrm{pH} 8.0)$, concentrated as described above, and stored at $-80{ }^{\circ} \mathrm{C}$. All proteins migrated as single bands via sodium dodecyl sulfate-polyacrylamide gel electrophoresis (SDS-PAGE). EcTrx1 and EcNTR were obtained by the same procedure using expression plasmids with the corresponding genes inserted in pET14a and pET15b, respectively, purchased from Eurofins MWG Operon (Ebersberg, Germany). BASI C144S was conjugated with 2-nitro-5-thiobenzoate (TNB) as reported previously. ${ }^{7}$ Yields were $10-20 \mathrm{mg}$ of wt and mutant proteins obtained from $1 \mathrm{~L}$ of bacterial culture, except that HvTrxh2 M88G was obtained in 10-fold smaller amounts. Experimental extinction coefficients $\left(\varepsilon_{280}\right)$ were determined by aid of amino acid analysis for preparations of Trxs and BASI, ${ }^{25}$ while NTR active sites were quantified by the FAD absorbance $\left(\varepsilon_{456}=11300 \mathrm{M}^{-1} \mathrm{~cm}^{-1}\right)$ as determined for $E$. coli NTR. ${ }^{26}$ Recombinant barley glutathione peroxidase HvGpx2 (Unigene entry AB096704) was an in-house preparation (kind gift of N. Navrot). 
Table 2. Pairs of Atoms Forming Intermolecular Contacts in Three Trx Complexes ${ }^{a}$

\begin{tabular}{|c|c|c|c|c|c|}
\hline \multicolumn{2}{|c|}{ HvTrxh2-BASI (PDB entry 2IWT) } & \multicolumn{2}{|c|}{ EcTrx1-PAPS reductase (PDB entry 2O8V) } & \multicolumn{2}{|c|}{ EcTrx1-NTR (PDB entry 1 F6M $)^{b}$} \\
\hline HvTrxh2 & BASI & EcTrxl & PAPS reductase & EcTrx1 & EcNTR \\
\hline M88 N & $\mathrm{C} 148 \mathrm{O}$ & & & I75 N & D139 OD1 \\
\hline M88 O & C148 N & $\mathrm{I} 75 \mathrm{O}$ & $\mathrm{C} 239 \mathrm{~N}$ & & \\
\hline A106 N & D146 O & A93 N & $\mathrm{R} 237 \mathrm{O}$ & & \\
\hline $\mathrm{E} 86 \mathrm{CB},{ }^{c} \mathrm{CD}^{c}$ & $\mathrm{E} 168^{c}$ & R73 NH1 & E238 OE2 & R73 N & G129 O \\
\hline $\mathrm{E} 86 \mathrm{CB},{ }^{c} \mathrm{CD}^{c}$ & $\mathrm{Q} 149^{c}$ & R73 NE & E243 OE1 & R73 NE & $\mathrm{R} 130 \mathrm{O}$ \\
\hline & & R73 NH2 & E243 OE1 & R73 NH2 & $\mathrm{R} 130 \mathrm{O}$ \\
\hline & & $\mathrm{R} 73 \mathrm{NH} 2^{d}$ & $\mathrm{E} 243 \mathrm{OE} 2^{d}$ & $\mathrm{R} 73 \mathrm{NH} 2$ & A237 O \\
\hline
\end{tabular}

${ }^{a}$ Unless stated otherwise, the contacts represent hydrogen bond interactions in the HvTrxh2-BASI, EcTrx1-PAPS reductase, and EcTrx1-NTR complexes involving residues corresponding to HvTrxh2 E86, M88, and A106. The information about hydrogen bonds and hydrophobic contacts was obtained from the Protein Data Bank and processed with the tool sum (http://www.ebi.ac.uk/thornton-srv/databases/pdbsum/). For a threedimensional image of the three H-bonds in the HvTrxh2-BASI complex, see Figure 3B of ref $7 .{ }^{b}$ In the structure of the EcTrx1-NTR complex containing four pairs of Trx-NTR chains, hydrogen bonds refer to interactions between chains $\mathrm{A}-\mathrm{C}$ and $\mathrm{E}-\mathrm{G}$. Between chains $\mathrm{B}-\mathrm{D}$ and $\mathrm{F}-\mathrm{H}$, there are some deviations that involve the side chain of $\mathrm{R} 73_{\mathrm{EcTrx1}} \cdot{ }^{c}$ van der Waals contacts. ${ }^{d}$ This interaction is defined as a salt bridge.

Spectrophotometric Assays of HvTrxh2 Mutants. In assays toward BASI, HvNTR2, and HvGpx2, activity was determined as the (turnover) number of disulfides reduced per second per molecule of Trx. In assays of activity toward BASI and $\mathrm{HvGpx} 2$, the consumption of $\mathrm{NADPH}$ was recorded using $0.2 \mu \mathrm{M}$ HvNTR2, found to be saturating. To obtain the background levels, NADPH consumption $\left(\varepsilon_{340}=6200 \mathrm{M}^{-1}\right.$ $\left.\mathrm{cm}^{-1}\right)$ or, in NTR assays, release of the TNB anion $\left(\varepsilon_{412}=\right.$ $13600 \mathrm{M}^{-1} \mathrm{~cm}^{-1}$ ) was monitored in the absence of Trx for 5 min. At least $45 \mathrm{~s}$ was used for evaluation of reduction rates in BASI and NTR assays. Activity toward BASI (final concentrations of 50 and $100 \mu \mathrm{M}$ ) was measured using $0.2 \mathrm{mM}$ $\mathrm{NADPH}$ in $0.1 \mathrm{M}$ Tris-HCl (pH 7.5), $2 \mathrm{mM}$ EDTA, and 2.0 $\mu \mathrm{M} \operatorname{Trx}$ (except $26 \mu \mathrm{M}$ for mutant M88P of very low activity) in a $100 \mu \mathrm{L}$ quartz cuvette, in at least duplicate. Disulfide reduction activities were linearly proportional to concentrations of both BASI and Trx and reported as second-order rate constants $\left(\mathrm{M}^{-1} \mathrm{~s}^{-1}\right)$. Mutants were screened for deficient recycling by HvNTR2 $(0.1 \mu \mathrm{M})$ in $0.1 \mathrm{M}$ Tris- $\mathrm{HCl}(\mathrm{pH} 7.5), 2$ $\mathrm{mM}$ EDTA, and $0.2 \mathrm{mM} \mathrm{NADPH}$, including BSA (0.1 mg/ $\mathrm{mL}$ ) and using $0.2 \mathrm{mM}$ 5,5'-dithiobis(2-nitrobenzoic acid) (DTNB) as final electron acceptor monitoring ( $1 \mathrm{~mL}$ plastic cuvettes) the formation of TNB anion above a background level of $0.005 \Delta A_{412} \mathrm{~min}^{-1}$ in the absence of Trx. At a minimum, triplicate experiments were performed. To determine $k_{\text {cat }}$ for HvNTR2 and $K_{\mathrm{M}}$ for Trx as the substrate, $50 \mathrm{nM}$ HvNTR2 was used with $0.25-10 \mu \mathrm{M}$ Trx in $0.1 \mathrm{M}$ potassium phosphate (pH 7.5), $2 \mathrm{mM}$ EDTA, BSA $(0.1 \mathrm{mg} / \mathrm{mL}), 0.2 \mathrm{mM}$ $\mathrm{NADPH}$, and $0.2 \mathrm{mM}$ DTNB. The Michaelis-Menten equation was fit to the data (Kaleidagraph, Synergy Software, Reading, PA). Activity against HvGpx2 was assayed $(100 \mu \mathrm{L}$ microtiter plate format) for $25 \mathrm{~min}$ with (subsaturating) $1.0 \mu \mathrm{M}$ Trx (15 $\mu \mathrm{M}$ HvTrxh2 M88P) using $0.2 \mu \mathrm{M}$ HvNTR2, $0.2 \mu \mathrm{M}$ HvGpx2, and $0.2 \mathrm{mM} \mathrm{NADPH}$ in $0.1 \mathrm{M}$ potassium phosphate ( $\mathrm{pH} 7.5$ ), $2 \mathrm{mM}$ EDTA, and $0.1 \mathrm{mg} / \mathrm{mL}$ BSA. Reactions were initiated by addition of tert-butyl peroxide to a final concentration of $1.0 \mathrm{mM}$; three independent duplicate assays were performed. Controls with and without wt HvTrxh2 were included in each microtiter plate. Under these conditions, the turnover number of wt HvTrxh2 $\left(0.045 \mathrm{~s}^{-1}\right)$ was defined as $100 \%$ activity. An assay for reduction of disulfide bonds in bovine insulin was adapted to the microtiter plate format and performed essentially as described previously. ${ }^{27}$ The reaction was initiated by adding DTT (final concentration of $0.33 \mathrm{mM}$ ) to $1.0 \mu \mathrm{M}$ Trx and $1 \mathrm{mg} / \mathrm{mL}$ bovine insulin in $100 \mathrm{mM}$ potassium phosphate ( $\mathrm{pH} 7.0), 0.2 \mathrm{mM}$ EDTA $(250 \mu \mathrm{L})$. Turbidity was monitored at $650 \mathrm{~nm}$, and the rate of absorbance change in the interval of $0.1-0.2$ absorbance unit was determined. The values obtained were compared to a standard curve of the rates from 0.2 to $1.0 \mu \mathrm{M}$ wt HvTrxh2 (Figure S1 of the Supporting Information).

DTT Reduction Kinetics. Assumed pseudo-first-order reaction mixtures of $\operatorname{Trx}(7 \mu \mathrm{M})$ and DTT $(100 \mu \mathrm{M})$ in reaction buffer $[0.1 \mathrm{M}$ sodium phosphate and $0.2 \mathrm{mM}$ EDTA $(\mathrm{pH} 7.0)]$ were incubated at room temperature. Reactions (188 $\mu \mathrm{L})$ were quenched at appropriate time points with $40 \%$ acetic acid $(62 \mu \mathrm{L})$ and analyzed by reversed phase high-performance liquid chromatography (RP-HPLC) at $30{ }^{\circ} \mathrm{C}$ (C18 column 3 $\mu \mathrm{m}, 300 \AA$, $4.6 \mathrm{~mm} \times 150 \mathrm{~mm}$; Dionex HPLC system) ${ }^{28}$ Reduced and oxidized proteins were separated by a gradient of acetonitrile (from 38 to $54 \%$ ) in $0.1 \%$ trifluoroacetic acid. Their relative amounts were obtained from the peak areas at $215 \mathrm{~nm}$ after integration with Chromeleon (Dionex).

Circular Dichroism Spectroscopy. Trx $(10 \mu \mathrm{M})$ was dialyzed against $20 \mathrm{mM}$ sodium phosphate $(\mathrm{pH} 7.0)$ (Slide-ALyzer cassettes, Pierce). CD spectra were recorded (Jasco J-600 $\mathrm{CD}$ spectrometer) at $25^{\circ} \mathrm{C}$ using a $1.0 \mathrm{~mm}$ quartz cuvette $(300$ $\mu \mathrm{L}$ ). Five scans from 250 to $190 \mathrm{~nm}$ were recorded per sample, and resulting spectra were smoothed and corrected for buffer blank.

Complete Reduction of Trx. Trx was reduced by $10 \mathrm{mM}$ DTT in $1 \mathrm{mM}$ EDTA for at least $30 \mathrm{~min}$ in the dark. Excess DTT was removed by gel filtration (NAP-5 column, GE Healthcare) using argon-purged reaction buffer [0.1 M sodium phosphate and 0.2 mM EDTA ( $\mathrm{pH} 7.0)]$, and the samples were stored on ice, protected from light, and used within the same day. The SH:Trx molar ratio was confirmed $(2.0 \pm 0.2)$ using $0.2 \mathrm{mM}$ DTNB with $0.2 \mathrm{mM}$ cystamine as a mediator in $3.0 \mathrm{M}$ guanidine $\mathrm{HCl}$ and $0.1 \mathrm{M}$ Tris- $\mathrm{HCl}(\mathrm{pH} 8.0){ }^{29}$

Determination of the HvTrxh2 M88P Redox Potential $\left(E^{\circ \prime}\right)$ by Equilibrium with EcTrx1. Using equilibrium reactions with the $\mathrm{NADPH} / \mathrm{NADP}^{+}$couple catalyzed by EcNTR, we first verified that the redox potential of the Histagged version of EcTrxl was $-270 \pm 1 \mathrm{mV}$. This "classical method" was performed according to Krause et al., ${ }^{30}$ employing the reaction buffer as stated above. EcTrxl was then used as the reference protein in direct protein-protein equilibrium (in reaction buffer) with HvTrxh2 M88P according to the method developed by Åslund et al. ${ }^{31}$ The redox reaction (in $100 \mu \mathrm{L}$ ) was initiated by mixing one protein in the reduced state with 
the other protein in its oxidized state in a 1:1 ratio at $\sim 50 \mu \mathrm{M}$ (and vice versa). The reaction mixture was allowed to equilibrate overnight $(16 \mathrm{~h})$ before the reaction was quenched by phosphoric acid $(0.67 \mathrm{M}, 100 \mu \mathrm{L})$ to a final $\mathrm{pH}$ of $\sim 2.0$, and the mixture $(150 \mu \mathrm{L})$ was loaded onto the C18 RP-HPLC column, equilibrated in $5 \%(\mathrm{v} / \mathrm{v})$ acetonitrile and $0.1 \%(\mathrm{v} / \mathrm{v})$ trifluoroacetic acid. The four protein species were eluted by a gradient of acetonitrile (from 40.5 to $62 \%$ ) in $0.1 \%(\mathrm{v} / \mathrm{v}$ ) trifluoroacetic acid over $25 \mathrm{~min}$ at a flow rate of $1 \mathrm{~mL} / \mathrm{min}$. The equilibrium constant was calculated in the direction of the reference being reduced (eq 1 ).

$$
K=\frac{\left[\mathrm{M} 88 \mathrm{P}_{\mathrm{ox}}\right]\left[\mathrm{EcTrx}_{\mathrm{red}}\right]}{\left[\mathrm{M} 88 \mathrm{P}_{\mathrm{red}}\right]\left[\mathrm{EcTrx}_{\mathrm{ox}}\right]}
$$

To gauge the loss of reducing equivalents to molecular oxygen during the aerobic incubation, samples with reduced protein only were included as controls.

Reduction of BASI Visualized by PEG Maleimide Incorporation. TMM $(\mathrm{PEG})_{12}$ (Thermo Scientific), an ethylmaleimide derivative linked to a trimethylated branched polyethylene glycol of $2.4 \mathrm{kDa}$ (apparent shift in SDS-PAGE of $>2.4 \mathrm{kDa}$ ), was used to label thiol groups. BASI and reduced Trx in an ice bath were both diluted to $20 \mu \mathrm{M}$ and mixed in reaction buffer $(400 \mu \mathrm{L})$, and aliquots $(20 \mu \mathrm{L})$ removed at appropriate intervals were reacted with $\operatorname{TMM}(\mathrm{PEG})_{12}(5 \mu \mathrm{L})$ to a final concentration of $1 \mathrm{mM}$. After $2 \mathrm{~h}$, the remaining $\operatorname{TMM}(\mathrm{PEG})_{12}$ was quenched by $50 \mathrm{mM}$ DTT. The samples were diluted in SDS sample buffer, and $2 \mu \mathrm{g}$ of BASI was loaded in each lane for SDS-PAGE.

Reduction of BASI C144S-TNB. BASI C144S-TNB was diluted in reaction buffer (100 $\mu \mathrm{L}$ quartz cuvette), and the baseline absorbance at $412 \mathrm{~nm}$ was recorded for $30 \mathrm{~s}$ at room temperature. Reduced Trx (or DTT) was added in a 2 -fold molar excess over BASI C144S-TNB (24 and $12 \mu \mathrm{M})$, and the reaction $(100 \mu \mathrm{L})$ was monitored at $10 \mathrm{~s}$ intervals. To obtain second-order reaction rate constants, the progress curve was linearly fit by Microsoft Excel to eq 2 .

$$
k \mathrm{t}=\frac{1}{[\mathrm{Trx}]_{0}-\left[\mathrm{BASI}^{*}\right]_{0}} \ln \frac{[\mathrm{Trx}]\left[\mathrm{BASI}^{*}\right]_{0}}{\left[\mathrm{BASI}^{*}\right][\mathrm{Trx}]_{0}}
$$

BASI* denotes the TNB activated form, BASI C144S-TNB.

\section{RESULTS}

Comparison of Intermolecular Contacts in Structures of Trx Complexes. Interacting atoms involving residues corresponding to the so-called "substrate recognition loop motif" in HvTrxh2 are compared in two Trx-target complexes, HvTrxh2-BASI and EcTrx1-PAPS reductase, and the EcTrx1-NTR complex (Figure 1 and Table 2)..$^{3,7,8}$ It should be noted that the EcTrx1-PAPS reductase and EcTrx1-NTR complexes have three and two additional hydrogen bond interactions, respectively (not included in Table 2). In comparison, the HvTrxh2-BASI complex appears to be a complex of lower affinity, possibly reflecting a fine-tuned regulation of $\alpha$-amylase/subtilisin inhibition.

In the EcTrx1-PAPS reductase complex, two hydrogen bonds involve $175_{\mathrm{EcTrx}} \mathrm{O}$ and $\mathrm{A} 93_{\mathrm{EcTrxl}} \mathrm{NH}$, corresponding to $\mathrm{M} 88_{\mathrm{HvTrxh} 2} \mathrm{O}$ and $\mathrm{A} 106_{\mathrm{HvTrxh}} \mathrm{NH}$, respectively, in the HvTrxh2-BASI complex. These interactions are not observed in the EcTrx1-NTR complex, where $I 75_{\mathrm{EcTrx1}} \mathrm{NH}$ forms hydrogen bonds to D139 $9_{\mathrm{EcNTR}}$ OD1. D139 $9_{\mathrm{EcNTR}}$ was suggested to be an acid/base catalyst influencing the nearby active site cysteines in EcNTR. ${ }^{32}$ On the basis of this observation, we predict that residues corresponding to EcTrx1 I75 are important in both target protein and NTR recognition.

E86 $6_{\text {HvTrxh2 }}$ from the cis-proline loop makes van der Waals contacts with Q149 and E168 in BASI (Figure 1 and Table 2). The latter residue has a functional role in the inhibition of barley $\alpha$-amylase as shown using the BASI mutants E168Q and E168T. ${ }^{33}$ E $86_{\text {HvTrxh2 }}$ corresponds to R73 $3_{\text {EcTrx1 }}$ that participates in multiple intermolecular interactions in the EcTrx1-PAPS reductase and EcTrx1-NTR complexes. E86 $6_{\text {HvTrxh2 }}$ and E168 $8_{\text {BASI }}$ are quite closely spaced in the HvTrxh2-BASI complex, $4.6 \AA$ being the shortest distance between the side chain carboxylate $\mathrm{OE}$ atoms. The carboxylate of $\mathrm{E} 86_{\mathrm{HvTrxh} 2}$ is $\sim 15 \AA$ from the active site disulfide of HvTrxh2, excluding a direct effect on cysteine reactivity. On the basis of the structure of the HvTrxh2-BASI complex, an E86 $\mathrm{R}_{\mathrm{HvTrxh} 2}$ mutant was designed to engineer electrostatic attraction toward BASI.

The comparison of HvTrxh2-BASI, EcTrx1-PAPS reductase, and EcTrx1-NTR complexes highlights possible key roles of E86, M88, and A106 in Trx-target protein and NTR recognition, motivating the mutational analysis presented here.

Apparent BASI Reduction. Reduction of BASI by Trx was analyzed in an assay coupled to HvNTR2-dependent NADPH oxidation. The disulfide reductase activity was linearly proportional to the concentration of BASI (Figure 2) and Trx and

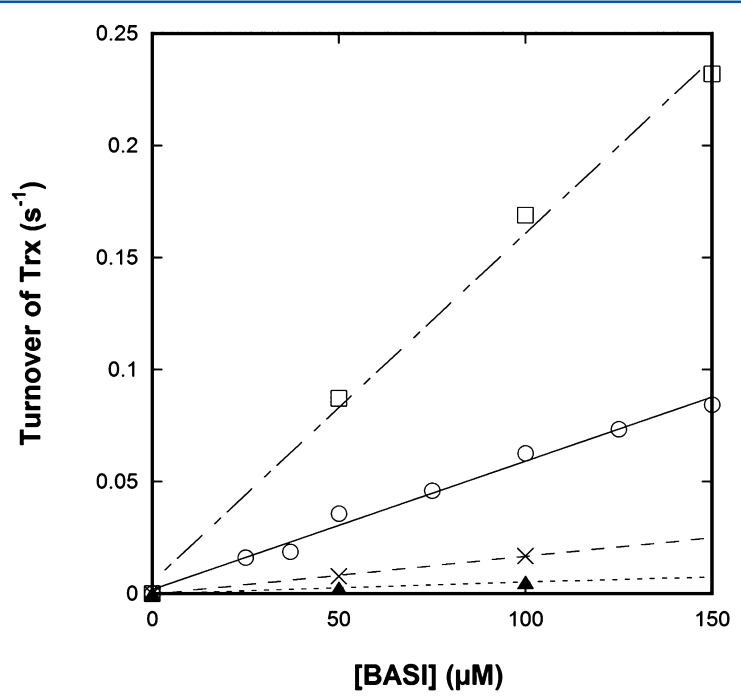

Figure 2. Second-order rate of the apparent BASI reduction. The concentration was $2.0 \mu \mathrm{M}$ for wt HvTrxh2 (O) and E86R ( $\square), 6 \mu \mathrm{M}$ for M88A $(\times)$, and $12 \mu \mathrm{M}$ for A106P $(\boldsymbol{\Delta})$. Rates of NADPH oxidation in $\Delta 340 \mathrm{~s}^{-1}$ were converted to rates of turnover $\left(\mathrm{s}^{-1}\right)$ of mutant or wt HvTrxh2.

expressed as second-order rate constants relative to that of wt HvTrxh2 (Table 3). The value of $550 \mathrm{M}^{-1} \mathrm{~s}^{-1}$ obtained for the wt is to the best of our knowledge the first disulfide reduction rate reported for one of the very large number of plant Trx targets identified in proteomic screens. ${ }^{11}$ Activity was reduced to a greater extent in M88 than in A106 mutants (Figure 3 and Table 3). M88G, M88A, and M88L showed 5, 30, and 75\% of wt activity toward BASI, respectively, whereas M88P completely lost activity; i.e., no detectable signal was obtained above the background level of NADPH oxidation (0.002 $\Delta 340$ $\min ^{-1}$ ), which represents the HvNTR2-dependent reduction of oxygen. Mutants A106P, A106G, and A106S showed 10, 63, and $113 \%$ of wt activity, respectively, while the bulky A106Y 
Table 3. Activity of HvTrxh2 Mutants ${ }^{a}$

\begin{tabular}{|c|c|c|c|c|}
\hline \multirow[b]{2}{*}{ HvTrxh2 mutant } & \multicolumn{4}{|c|}{ activity relative to that of wild-type HvTrxh2 (1.0) } \\
\hline & BASI & DTNB/NTR & Gpx & insulin \\
\hline E86R & $3.01 \pm 0.18$ & $0.83 \pm 0.02$ & $0.53 \pm 0.02$ & $1.25 \pm 0.13$ \\
\hline M88G & $0.06 \pm 0.01$ & $0.15 \pm 0.002$ & $0.13 \pm 0.02$ & $0.69 \pm 0.07$ \\
\hline M88A & $0.30 \pm 0.01$ & $0.31 \pm 0.01$ & $0.25 \pm 0.03$ & $0.60 \pm 0.05$ \\
\hline M88P & $\mathrm{nd}^{b}$ & $0.004 \pm 0.002$ & $0.010 \pm 0.005$ & $0.10 \pm 0.03$ \\
\hline M88L & $0.74 \pm 0.06$ & $0.47 \pm 0.01$ & $0.70 \pm 0.05$ & $0.57 \pm 0.06$ \\
\hline A106G & $0.63 \pm 0.03$ & $0.45 \pm 0.04$ & $0.86 \pm 0.08$ & $1.11 \pm 0.09$ \\
\hline A106S & $1.13 \pm 0.02$ & $0.74 \pm 0.02$ & $0.82 \pm 0.04$ & $1.08 \pm 0.14$ \\
\hline A106P & $0.090 \pm 0.002$ & $0.98 \pm 0.04$ & $0.52 \pm 0.10$ & $0.90 \pm 0.10$ \\
\hline A106Y & $0.27 \pm 0.02$ & $1.29 \pm 0.09$ & $0.70 \pm 0.06$ & $0.81 \pm 0.07$ \\
\hline
\end{tabular}

${ }^{a}$ The activity is normalized to the wt value, and 1.0 represents $550 \mathrm{M}^{-1} \mathrm{~s}^{-1}$ for the apparent reduction rate of BASI, 1.2 DTNB disulfides Trx ${ }^{-1} \mathrm{~s}^{-1}$ in the DTNB-NTR assay, and $0.045 \mathrm{Gpx}$ disulfide $\mathrm{Trx}^{-1} \mathrm{~s}^{-1}$, respectively. For insulin, an activity of 1.0 relates to the rate of absorbance change at 650 $\mathrm{nm}$ in the interval between 0.1 and 0.2 of wt HvTrxh2 (see Experimental Procedures and Figure S1 of the Supporting Information). Reduction of BASI is based on the average of two measurements. ${ }^{b}$ Activity with HvTrxh2 M88P was not detectable.

substitution resulted in $30 \%$ activity (Figure 3). Very remarkably, mutant E86R had 3-fold higher activity toward BASI than wt HvTrxh2 (Figures 2 and 3).

Recycling by HvNTR2. To screen for deficiency in recycling by HvNTR2, the HvTrxh2 mutants were assayed with DTNB as the final electron acceptor. The NTR assay has by far the best signal-to-noise ratio of the four multipleturnover assays used in this study. Thus, because of the catalytic efficiency of NTR and the high molar extinction coefficient of the TNB anion, a residual activity of $<1 \%$ can be accurately determined in this assay as opposed to the reduction of BASI, HvGpx2, and insulin. Using $100 \mathrm{nM}$ HvNTR2, 25-100 nM HvTrxh2 gave a linear dependence of activity (data not shown). Under these conditions, the rate of turnover of wt HvTrxh2 was $1.2 \mathrm{~s}^{-1}$. The order of decreasing activities for HvTrxh2 (M88L > M88A > M88G > M88P) against HvNTR2 was the same as that toward BASI (Table 3). Mutant M88G displayed considerably lowered activity (15\% of wt), while M88P had only $0.4 \%$ activity. The apparent diminished BASI disulfide reduction by these mutants may therefore be related to a poor recycling of the mutants by HvNTR2. HvNTR2 recycled mutants E86R and A106P with activity similar to that of wt HvTrxh2 despite their 3-fold increase and 11-fold decrease, respectively, in the apparent level of BASI reduction (Figure 3). In light of the conservation of A106 (Table 1), HvNTR2 catalyzed reduction of A106Y surprisingly well.

The kinetics of selected HvTrxh2 mutants revealed that the low catalytic efficiency toward M88G stemmed from an increased $K_{\mathrm{M}}$ of $8.4 \pm 1.7 \mu \mathrm{M}$ compared to a value of $1.75 \pm$ $0.075 \mu \mathrm{M}$ for wt HvTrxh2 (Figure 4A). The apparent $k_{\text {cat }}$ of HvNTR2 $\left(12.5 \mathrm{~s}^{-1}\right)$ was not affected, although the M88 $8_{\text {HvTrxh2 }}$ side chain is close to the active site cysteines. A linear dependence on the concentration of M88P was observed in contrast to the substrate saturation curves found for wt HvTrxh2 and its mutants (Figure 4A,B). The catalytic efficiency for M88P decreased 300-fold to $2.2 \times 10^{4} \mathrm{M}^{-1} \mathrm{~s}^{-1}$ (from $7.1 \times 10^{6} \mathrm{M}^{-1} \mathrm{~s}^{-1}$ for wt HvTrxh2), and the curve demonstrates the deficient binding to HvNTR2.

Apparent Reduction of Glutathione Peroxidase (Gpx). Gpxs from plants are Trx-dependent thiol peroxidases that exhibit sequence homology to classical glutathione-dependent mammalian Gpx. ${ }^{34}$ Briefly, the catalytic cycle of Trx-dependent Gpx is initiated when the so-called peroxidatic cysteine is oxidized to a sulfenic acid concomitant with peroxide reduction. This sulfenic acid is then attacked by a second "resolving"

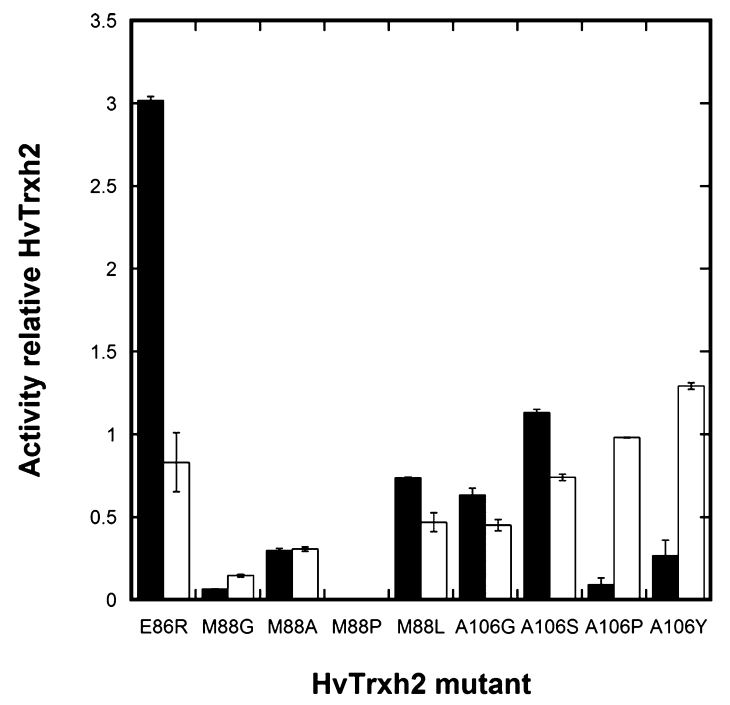

Figure 3. Apparent HvTrxh2 reduction of BASI and recycling by HvNTR2. The activity relative to that of wt HvTrxh2 (1.0) is shown for the BASI (black) and HvNTR2 (white) assays.

cysteine in Gpx, resulting in the formation of an intramolecular disulfide that is reduced by Trx to regenerate Gpx. wt HvTrxh2 and mutants were analyzed for specific activity with barley HvGpx2 as a catalytic disulfide target in the presence of HvNTR2/NADPH as the Trx recycling system. The M88P mutant was the least active as in the BASI assay and probably influenced by inefficient recycling by HvNTR2 (Table 3). Furthermore, the activities of mutants M88G, M88A, and M88L of 13, 25, and 70\%, respectively, followed the trend as in the BASI and HvNTR2 assays. Overall, the A106 mutants showed only minor decrease in activity toward $\mathrm{HvGpx2}$, and the $52 \%$ activity of A106P was much higher than that toward BASI (Figure 2). HvTrxh2 E86R had reduced activity toward HvGpx2 (53\% of wt), as opposed to its 3-fold increased activity toward BASI.

Reduction of Insulin. HvTrxh2 mutants were analyzed for NTR-independent activity using insulin as a substrate in the presence of DTT, a widely used Trx assay. ${ }^{27,35}$ Insulin is a good substrate, giving a second-order rate constant of $2.4 \times 10^{4} \mathrm{M}^{-1}$ $\mathrm{s}^{-1}$ for HvTrxh2, 28,35 which is more than 1 order of magnitude higher than that with BASI as the substrate. In agreement with the other three steady state assays, HvTrxh2 M88P had the 

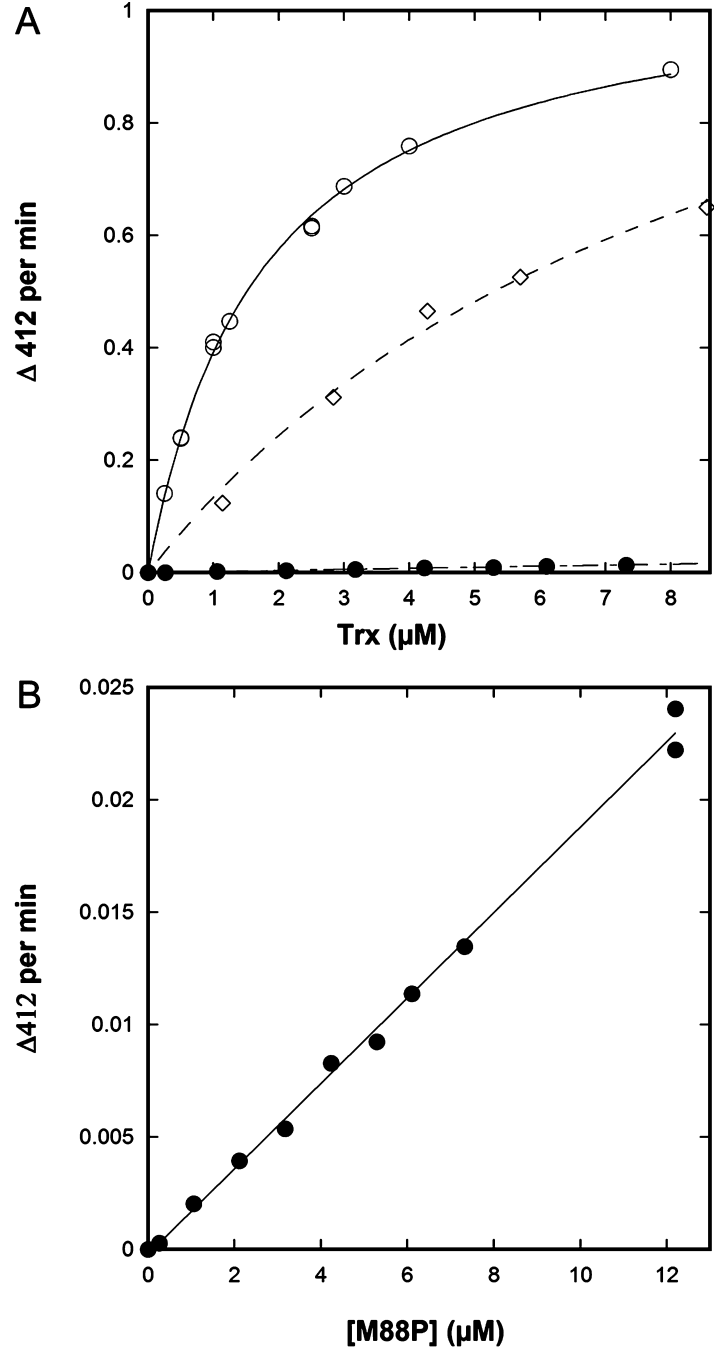

Figure 4. Reduction of wt HvTrxh2 (O), M88G $(\diamond)$, and M88P $(\bullet$ by HvNTR2. (A) The kinetic parameters were determined in the presence of $50 \mathrm{nM}$ HvNTR2. Evaluation indicated $k_{\mathrm{cat}}$ and $K_{\mathrm{M}}$ values of $12.5 \mathrm{~s}^{-1}$ and $1.75 \pm 0.078 \mu \mathrm{M}$, respectively, for wt HvTrxh2. The $k_{\text {cat }}$ was similar for HvTrxh2 M88G, but the $K_{\mathrm{M}}$ increased to $8.4 \pm 1.7$ $\mu \mathrm{M}$. (B) Rate with HvTrxh2 M88P with an enlarged scale on the $y$ axis.

lowest activity (10\%), other M88 mutants displayed 50-70\% of the wt activity, and the activity of E86R and A106 mutants was essentially unaffected (Table 3). The higher residual activity of mutant M88P against insulin compared to those against BASI, Gpx2, and HvNTR2 may reflect the fact that negative effects on the NTR interaction are bypassed by using DTT as a reductant.

Reduction by DTT. As HvTrxh2 M88P gave very low activity in assays using HvNTR2/NADPH, the reactivity of its dithiol/disulfide active site should be assessed using an approach not involving protein-protein interactions. In the case of EcTrxl, single-turnover reduction by DTT was monitored by the redox-dependent fluorescence change, ${ }^{27}$ but HvTrxh2 is lacking the equivalent of W28 in EcTrx1 and shows no such transition signal. ${ }^{28}$ Here, the rate of reduction of HvTrxh2 by DTT was determined using acid quenching followed by HPLC quantification of reduced and oxidized forms (Figure S2 of the Supporting Information). ${ }^{28,31}$ DTT reduced mutant M88P with a rate constant of $21 \mathrm{M}^{-1} \mathrm{~s}^{-1}$, which is approximately 5-fold slower than for wt (Figure 5).

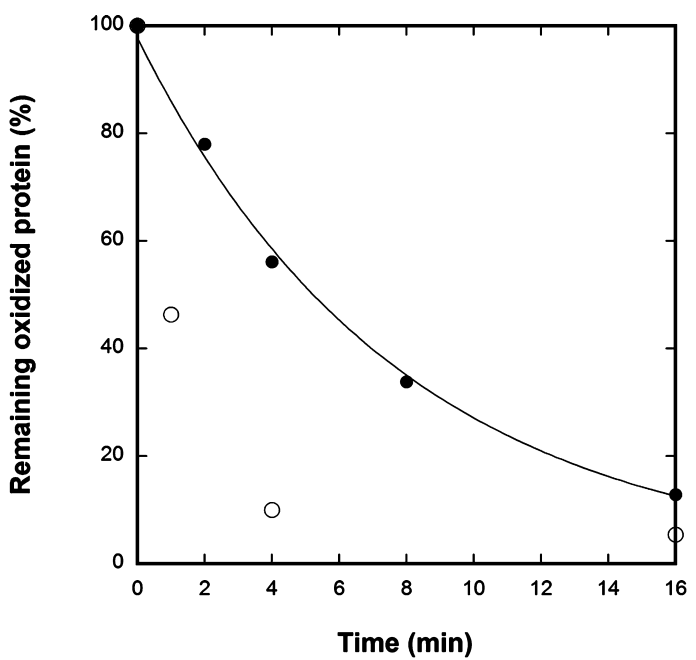

Figure 5. Reduction of wt HvTrxh2 and mutant M88P by DTT. The ratios between oxidized and reduced forms of wt HvTrxh2 (O) and M88P (O) incubated with $100 \mu \mathrm{M}$ DTT was determined by HPLC of acid-quenched reaction mixtures. The data were fit to a singleexponential function indicating a rate of $0.128 \mathrm{~min}^{-1}\left(t_{1 / 2}=5.4 \mathrm{~min}\right)$ for HvTrxh2 M88P. Assuming pseudo-first-order conditions, the rate constant is $21 \mathrm{M}^{-1} \mathrm{~s}^{-1}$. The rate for wt HvTrxh2 was estimated to be $\sim 5$ times higher, but the data do not fit to a single-exponential reaction and therefore are not displayed with the curve fit. Chromatograms of the $4 \mathrm{~min}$ time points are displayed in Figure S2 of the Supporting Information.

CD Spectroscopy. The mutants having very low or no activity in the various assays were subjected to $\mathrm{CD}$ spectroscopy to probe changes in secondary structure. Only slight differences in $\mathrm{CD}$ spectra are observed among wt HvTrxh2, M88G, M88P, and A106P, verifying that the proteins are properly folded (Figure S3 of the Supporting Information).

Redox Potential of HvTrxh2 M88P. The redox potential of HvTrxh2 M88P was determined by direct protein-protein equilibrium with EcTrx1 and separation of reduced and oxidized forms by HPLC according to the method developed by Åslund et al. ${ }^{31}$ During the aerobic overnight incubation, control samples of reduced HvTrxh2 M88P were less stable than those of EcTrxl and retained 92 and $96 \%$ of the reduced form, respectively (data not shown). This loss of reducing equivalents to molecular oxygen did not rule out observations of reliable equilibria (Figure 6), and an equilibrium constant $(K)$ of $1.25 \pm 0.12$ was determined. This corresponds to a difference of $3 \pm 1 \mathrm{mV}$, with HvTrxh2 M88P as the more reducing species. Using a kinetic approach, the redox potential of wt HvTrxh2 was previously determined to be very close to that of EcTrx1. ${ }^{28}$ It can therefore be concluded that the redox potential of HvTrxh2 M88P is essentially unchanged.

Single-Turnover Reduction of BASI. Chemically reduced wt HvTrxh2, M88P, and A106P were incubated with BASI (20 $\mu \mathrm{M})$ at a 1:1 molar ratio to analyze disulfide reduction in BASI, in a manner independent of NTR recycling, by modifying released BASI thiol groups with $\mathrm{TMM}(\mathrm{PEG})_{12}$. SDS-PAGE analyses demonstrated that wt HvTrxh2 and the two mutants partially reduced BASI (Figure S4 of the Supporting Information). To quantify the reductive capacity of HvTrxh2 mutants on the BASI C144-C148 disulfide, an activated singlecysteine BASI C144S mutant was employed in which the lone exposed cysteine residue (C148) is disulfide-bonded to TNB (C144S-TNB). The second disulfide, C44-C93, in BASI is 

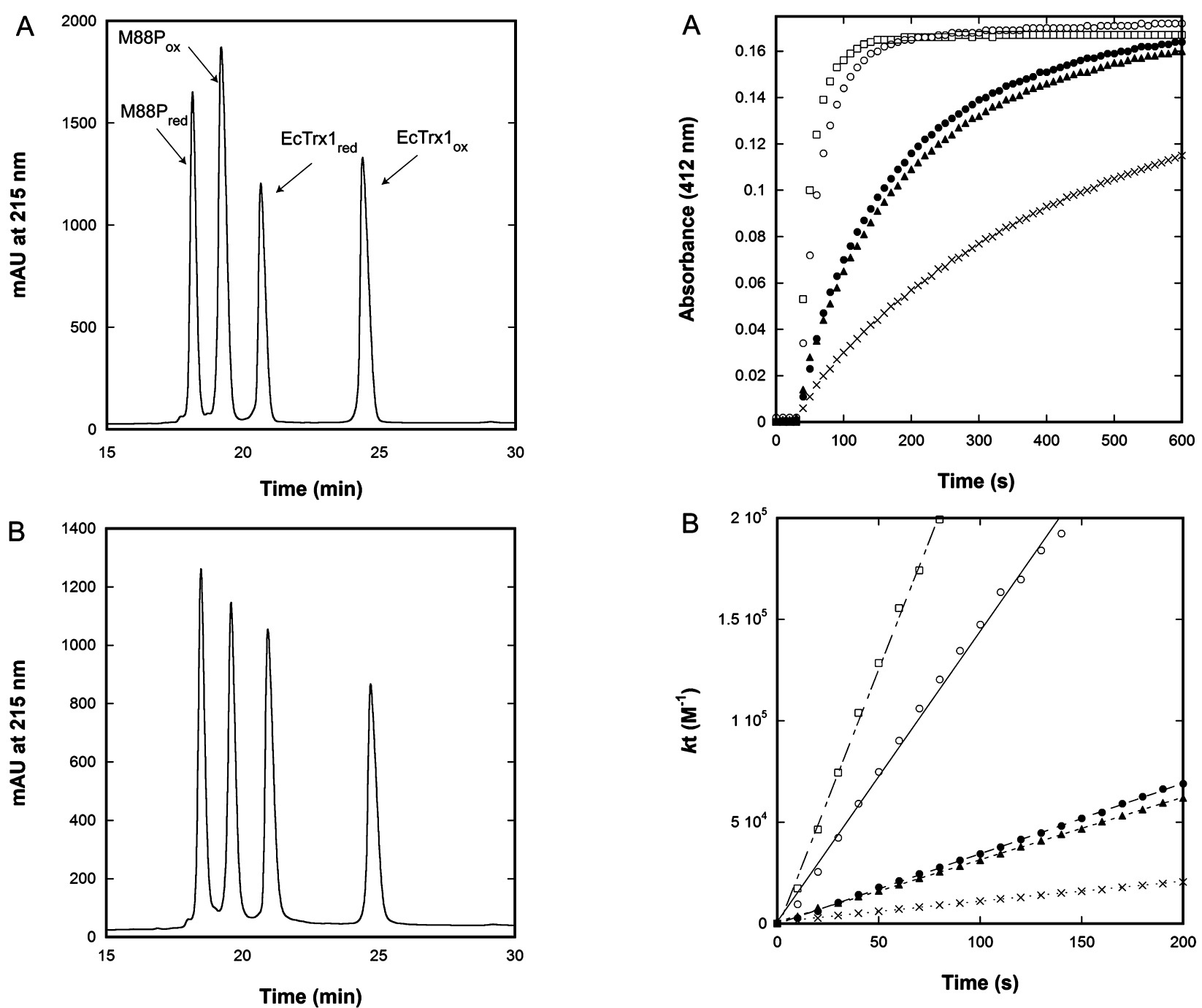

Figure 6. Redox equilibria between HvTrxh2 M88P and EcTrx1. The reactions were analyzed after the mixtures had been incubated for $16 \mathrm{~h}$, and the integrated peak areas were used to calculate the equilibrium constant $(K)$. (A) HPLC chromatogram of a reaction started with reduced EcTrx1 and oxidized HvTrxh2 M88P $(K=1.10)$. (B) HPLC chromatogram of a reaction started with reduced HvTrxh2 M88P (slight excess) and oxidized EcTrx $(K=1.15)$ (see Experimental Procedures for details).

known to be very poorly reduced by HvTrxh2. ${ }^{16}$ The release of TNB anion from the BASI C144S-TNB complex with a 2-fold molar excess of fully reduced wt HvTrxh2, M88P, A106P, and E86R or DTT was measured at $412 \mathrm{~nm}$ (Figure 7A). In contrast to the reduction of wt BASI, as indicated by incorporation of $\mathrm{TMM}(\mathrm{PEG})_{12}$, reduction of the activated BASI C144S-TNB complex was driven to completion and the efficiencies of wt HvTrxh2 and the mutant (and of DTT) were given by the second-order rate constants (Figure 7B). It is important to point out that only the initial nucleophilic attack by $\operatorname{Trx}$ is monitored in this single-turnover assay. Noticeably, HvTrxh2 E86R gave higher reactivity with a $k$ of $2500 \mathrm{M}^{-1} \mathrm{~s}^{-1}$ as compared to a $k$ of $1550 \mathrm{M}^{-1} \mathrm{~s}^{-1}$ for wt (Figure 7B). By contrast to the behavior in the HvNTR2-dependent BASI assay, mutants A106P and M88P lost reactivity to the same extent $\left(k=300-350 \mathrm{M}^{-1} \mathrm{~s}^{-1}\right)$. Both mutants were more reactive than DTT $\left(k=100 \mathrm{M}^{-1} \mathrm{~s}^{-1}\right)$ in the reduction of the BASI C144S-TNB complex.

Figure 7. Single turnover with the BASI C144S-TNB complex. (A) Background absorbance of the BASI C144S-TNB complex at $412 \mathrm{~nm}$ was recorded before addition of a 2 -fold excess of dithiol reductant $(24$ $\mu \mathrm{M})$ with either wt $\operatorname{Trxh} 2(\mathrm{O}), \operatorname{E86R}(\square), \operatorname{M88P}(\boldsymbol{\bullet})$, or A106P (A) or DTT $(\times)$. (B) Evaluation of data from panel A according to eq 2 (see Experimental Procedures). The linear curves indicate secondorder reaction rate constants ( $k$ ) of 1550 (wt HvTrxh2), 2500 (E86R), 350 (M88P), 310 (A106P), and $100 \mathrm{M}^{-1} \mathrm{~s}^{-1}$ (DTT). Data points up to $70 \mathrm{~s}$ for E86R, $140 \mathrm{~s}$ for wt HvTrxh2, and $200 \mathrm{~s}$ for M88P, A106P, and DTT were used to determine the rate constants.

\section{DISCUSSION}

The dithiol active site WCGPC sequence in Trxs has been thoroughly investigated. ${ }^{36}$ This study concerns two neighboring Trx loops called the cis-proline and the glycine loop (Figure 1) contributing intermolecular hydrogen bonds in the HvTrxh2BASI complex, which appear to be central for the rapid reduction of the BASI C144-C148 disulfide. Mutant A106P, not able to act as a hydrogen bond donor, showed only $10 \%$ apparent reduction of the BASI disulfide. Different replacements of A106 indicate that the side chain may also contribute to the reactivity toward BASI. Importantly, mutant A106P was efficiently recycled by HvNTR2 and also reacted fairly efficiently with insulin and HvGpx2. Together, these data provide strong evidence that the formation of hydrogen bonds between HvTrxh2 A106 NH and the substrate does not represent a universal requirement essential for Trx function and 
recycling by NTR. The A106 NH hydrogen bond may be important for reduction of PAPS reductase and methionine sulfoxide reductase because homologues of A106 in Trx complexes with these target proteins participate in similar intermolecular backbone-backbone hydrogen bonds as observed in the HvTrxh2-BASI complex. ${ }^{7,8,10}$ While the role of this highly conserved alanine residue was not previously investigated by mutagenesis, the invariant preceding glycine residue (G92 of EcTrx1) has previously been identified as being critical for interactions with EcNTR and bacteriophage T7 DNA polymerase. ${ }^{37}$

The side chain of HvTrxh2 M88 is important for efficient target disulfide reduction as demonstrated by the same order of decreasing activity found for HvTrxh2 (wt > M88L > M88A > M88G) toward BASI, Gpx, and HvNTR2 (Table 3). The results are consistent with observed favorable van der Waals contacts involving the M88 side chain in the HvTrxh2-BASI complex. ${ }^{7}$ One can speculate that these interactions are less relevant for the exceptionally fast Trx-catalyzed reduction of disulfides in insulin. For mutant M88P, the effect of the loss of one of the three backbone hydrogen bonds to BASI was not conclusively demonstrated because the mutant was severely deficient in recycling by NTR. Moreover, it was affected in terms of the chemical reactivity of its active site cysteines (Figure 5), although it has an essentially unperturbed redox potential (Figure 6). The shortcomings of HvTrxh2 M88P thus appear to be of a kinetic nature. The M88P substitution perhaps induces strain transmitted to the neighboring cisproline [P89 (Table 1)], an invariant key residue of the Trx superfamily. ${ }^{21,36}$ The position of $\mathrm{M} 88_{\mathrm{HvTrxh} 2}$ is occupied by an isoleucine residue in EcTrx1 (Table 1), and a comprehensive mutational analysis, including determination of the structure of EcTrx1 I75T, demonstrated that this "cisPro minus 1 residue" is a general activity regulator of Trx fold proteins. ${ }^{38}$ EcTrx1 I75P, however, was not generally more negatively affected than mutants with charged side chains (K, R, H, E, and D), and I75P had $\sim 10 \%$ residual activity toward insulin with either DTT or NTR as the reductant, which is similar to the results with HvTrxh2 M88P in the case of DTT but different from the results of the NTR recycling assay using DTNB as the final electron acceptor (Table 3). In the two different NTRindependent single-turnover BASI reduction assays, mutant M88P performed like A106P (Figure S4 of the Supporting Information and Figure 7). According to the HvTrxh2-BASI complex, mutants M88P and A106P each lack one hydrogen bond to BASI compared to wt HvTrxh2 (Table 2 and Figure 1). In the single-turnover assay with the activated BASI C144S-TNB complex, mutants M88P and A106P were better than DTT (Figure 7). wt HvTrxh2 and M88P have redox potentials similar to that of EcTrx1 $(-270 \mathrm{mV})$ and are thus much less thermodynamically favorable reducing agents than DTT $\left(E^{\circ \prime}=-310 \mathrm{mV}\right){ }^{28,39}$ Accordingly, the higher rate of HvTrxh2 M88P compared to that of DTT is consistent with the remaining specificity against BASI.

In terms of HvNTR2 recycling, the loss of the hydrogen bond from HvTrxh2 M88 NH may affect the $\mathrm{p} K_{\mathrm{a}}$ or the orientation of D149 $9_{\mathrm{HvNTR} 2}$. This aspartate residue is conserved among low-molecular weight NTRs, positioned close to the active site cysteines ( $\mathrm{SACA} /{ }_{\mathrm{T}} \mathrm{CDG}$ for barley, yeast, and E. coli NTR) and suggested to act as the catalytic acid/base. ${ }^{32}$ Thus, the mutants EcNTR D139L and yeast NTR1 D146A showed no steady state activity. ${ }^{32,40}$ If an interaction between $\mathrm{M} 88_{\mathrm{HvTrxh} 2} \mathrm{NH}$ and the carboxylate group of D149 ${ }_{\mathrm{HvNTR} 2}$ contributes to substrate-assisted catalysis, it may partly explain the large activity decrease (300-fold) of mutant M88P in this study (Figure 4). In the recent structure of the human (Homo sapiens) high-molecular weight HsNTR in complex with HsTrx1 (HsNTR1-Trx1), M74 ${ }_{\mathrm{HsTrx}} \mathrm{NH}$ (corresponding to $\mathrm{M} 88_{\mathrm{HvTrxh} 2} \mathrm{NH}$ ) is a donor in one of only two intermolecular hydrogen bonds and the acceptor backbone carbonyl group belongs to the catalytic selenocysteine residue. ${ }^{4}$ In this respect, the HsNTR1-Trx1 complex resembles the HvTrxh2-BASI complex and not the EcTrx1-NTR complex, in which $175_{\mathrm{EcTrx}}$ $\mathrm{NH}$ is hydrogen bonded to the side chain of D139 $9_{\mathrm{EcNTR}}$ involved in acid/base catalysis. The comparison thus suggests different roles of the cisPro minus 1 residue $\mathrm{NH}$ group for interactions with low- and high-molecular weight NTR.

The side chain of $R 73_{\mathrm{EcTrx}}$ protrudes at the protein surface and appears to play central roles in stabilizing the EcTrx1PAPS and EcTrx1-NTR complexes (Table 2). The importance

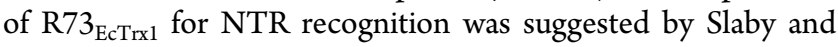
Holmgren in 1979 on the basis of the observation that tryptic cleavage at $\mathrm{R} 73$ in EcTrx1 [R GIP (Table 1)] severely impaired activity toward EcNTR. ${ }^{41}$ These findings were corroborated in a recent study in which EcTrx1 R73D and R73G had 0.6 and 3.8\% activity, respectively, with EcNTR but retained the insulin disulfide reductase activity. ${ }^{42}$ In HvTrxh2, and in most of the known plant h-type Trx, a glutamic acid (HvTrxh2 E86) corresponds to R73 $3_{\text {EcTrxl }}$. In yeast Trx, the position is occupied by a serine residue (Table 1). Mutant E86R retained almost full activity with barley HvNTR2, indicating that a strong determinant of the interaction between NTR and Trx evolved differently in plants, yeast, and bacteria. In this context, bacteriophage T4 glutaredoxin, the specific hydrogen donor of phage ribonucleotide reductase (originally called T4 thioredoxin), remains an intriguing example of molecular evolution by having leucine at the position corresponding to $\mathrm{R} 73_{\mathrm{EcTrx} 1}$. T4 glutaredoxin is efficiently reduced by glutathione as well as by EcNTR, and viral replication is therefore supported by both cellular reduction systems. ${ }^{43,44}$ The strikingly 3-fold increased activity of E86R toward the BASI disulfide is possibly a result of an electrostatic contact to $\mathrm{E} 168_{\mathrm{BASI}}$. In contrast to $\mathrm{R} 73_{\mathrm{EcTrx} 1}$, E86 $6_{\mathrm{HvTrxh} 2}$ seems not to be restricted by NTR interaction, and this residue may thus evolve and modulate activities toward target disulfides.

In conclusion, mutational analysis highlights the importance of key residues at the active site surface of Trx for interactions with target proteins and the NTR in recycling, as demonstrated by remarkable changes in activity profiles of single-amino acid variants. These findings add novel insight into the molecular basis of Trx target recognition that is relevant for other Trx fold oxidoreductases, e.g., glutaredoxins, and facilitates the development of catalysts with altered substrate specificities.

\section{ASSOCIATED CONTENT}

\section{Supporting Information}

One table and four figures. This material is available free of charge via the Internet at http://pubs.acs.org.

\section{AUTHOR INFORMATION}

\section{Corresponding Author}

*Telephone: +45 4525 5503. Fax: +45 4588 6307. E-mail: ph@ bio.dtu.dk. 


\section{Present Address}

${ }^{\dagger}$ EMBL Heidelberg, Meyerhofstrasse 1, 69117 Heidelberg, Germany.

\section{Funding}

This work was supported by the Danish Council for Technology and Production Sciences (FTP, Grant 274-080413) and the Carlsberg Foundation. K.M. received a Ph.D. scholarship from the Technical University of Denmark.

\section{Notes}

The authors declare no competing financial interest.

\section{ACKNOWLEDGMENTS}

Aida Curovic is acknowledged for technical assistance. Anne Blicher is thanked for performing amino acid analysis and Nicolas Navrot for providing HvGpx2. We are grateful to Birthe Kragelund for helpful discussions about the interpretation of CD spectra.

\section{ABBREVIATIONS}

BASI, barley $\alpha$-amylase/subtilisin inhibitor; CD, circular dichroism; DTNB, 5,5'-dithiobis(2-nitrobenzoic acid); EcTrx1, E. coli thioredoxin 1; EcNTR, E. coli NADPHdependent thioredoxin reductase; $\mathrm{HvGpx} 2$, barley glutathione peroxidase 2; HvNTR2, barley NADPH-dependent thioredoxin reductase 2; HvTrxh1, barley thioredoxin h1; HvTrxh2, barley thioredoxin h2; PAPS, 3'-phosphoadenosine $5^{\prime}$-phosphosulfate; PDB, Protein Data Bank; TNB, 2-nitro-5-thiobenzoate; wt, wild-type.

\section{REFERENCES}

(1) Arnér, E. S. J., and Holmgren, A. (2000) Physiological functions of thioredoxin and thioredoxin reductase. Eur. J. Biochem. 267, 61026109 .

(2) Williams, C. H. J. (1995) Mechanism and structure of thioredoxin reductase from Escherichia coli. FASEB J. 9, 1267-1276.

(3) Lennon, B. W., Williams, C. H., Jr., and Ludwig, M. L. (2000) Twists in catalysis: Alternating conformations of Escherichia coli thioredoxin reductase. Science 289, 1190-1194.

(4) Fritz-Wolf, K., Kehr, S., Stumpf, M., Rahlfs, S., and Becker, K. (2011) Crystal structure of the human thioredoxin reductasethioredoxin complex. Nat. Commun. 2, 383.

(5) Qin, J., Clore, G. M., Kennedy, W. M., Huth, J. R., and Gronenborn, A. M. (1995) Solution structure of human thioredoxin in a mixed disulfide intermediate complex with its target peptide from the transcription factor NF $\kappa$ B. Structure 3, 289-297.

(6) Qin, J., Clore, G. M., Kennedy, W. P., Kuszewski, J., and Gronenborn, A. M. (1996) The solution structure of human thioredoxin complexed with its target from Ref-1 reveals peptide chain reversal. Structure 4, 613-620.

(7) Maeda, K., Hägglund, P., Finnie, C., Svensson, B., and Henriksen, A. (2006) Structural basis for target protein recognition by the protein disulfide reductase thioredoxin. Structure 14, 1701-1710.

(8) Chartron, J., Shiau, C., Stout, C. D., and Carroll, K. S. (2007) 3'Phosphoadenosine-5'-phosphosulfate reductase in complex with thioredoxin: A structural snapshot in the catalytic cycle. Biochemistry 46, 3942-3951.

(9) Li, Y., Hu, Y., Zhang, X., Xu, H., Lescop, E., Xia, B., and Jin, C. (2007) Conformational fluctuations coupled to the thiol-disulfide transfer between thioredoxin and arsenate reductase in Bacillus subtilis. J. Biol. Chem. 282, 11078-11083.

(10) Ma, X. X., Guo, P. C., Shi, W. W., Luo, M., Tan, X. F., Chen, Y., and Zhou, C. Z. (2011) Structural plasticity of the thioredoxin recognition site of yeast methionine S-sulfoxide reductase Mxr1. J. Biol. Chem. 286, 13430-13437.
(11) Montrichard, F., Alkhalfioui, F., Yano, H., Vensel, W. H., Hurkman, W. J., and Buchanan, B. B. (2009) Thioredoxin targets in plants: The first 30 years. J. Proteomics 72, 452-474.

(12) Meyer, Y., Vignols, F., and Reichheld, J. P. (2002) Classification of plant thioredoxins by sequence similarity and intron position. Methods Enzymol. 347, 394-402.

(13) Buchanan, B. B., and Balmer, Y. (2005) Redox regulation: A broadening horizon. Annu. Rev. Plant Biol. 56, 187-220.

(14) Jiao, J., Yee, B. C., Kobrehel, K., and Buchanan, B. B. (1992) Effect of thioredoxin-linked reduction on the activity and stability of the Kunitz and Bowman-Birk soybean trypsin inhibitor proteins. J. Agric. Food Chem. 40, 2333-2336.

(15) Maeda, K., Finnie, C., and Svensson, B. (2004) Cy5 maleimide labelling for sensitive detection of free thiols in native protein extracts: Identification of seed proteins targeted by barley thioredoxin $h$ isoforms. Biochem. J. 378, 497-507.

(16) Maeda, K., Finnie, C., and Svensson, B. (2005) Identification of thioredoxin $\mathrm{h}$-reducible disulphides in proteomes by differential labelling of cysteines: Insight into recognition and regulation of proteins in barley seeds by thioredoxin h. Proteomics 5, 1634-1644.

(17) Hägglund, P., Bunkenborg, J., Maeda, K., and Svensson, B. (2008) Identification of thioredoxin disulfide targets using a quantitative proteomics approach based on isotope-coded affinity tags. J. Proteome Res. 7, 5270-5276.

(18) Hägglund, P., Bunkenborg, J., Yang, F., Harder, L. M., Finnie, C., and Svensson, B. (2010) Identification of thioredoxin target disulfides in proteins released from barley aleurone layers. J. Proteomics $73,1133-1136$

(19) Svensson, B., Fukuda, K., Nielsen, P. K., and Bønsager, B. C. (2004) Proteinaceous $\alpha$-amylase inhibitors. Biochim. Biophys. Acta 1696, 145-156.

(20) Vallée, F., Kadziola, A., Bourne, Y., Juy, M., Rodenburg, K. W., Svensson, B., and Haser, R. (1998) Barley $\alpha$-amylase bound to its endogenous protein inhibitor BASI: Crystal structure of the complex at $1.9 \AA$ A resolution. Structure 6, 649-659.

(21) Martin, J. L. (1995) Thioredoxin: A fold for all reasons. Structure 3, 245-250.

(22) Gelhaye, E., Rouhier, N., Navrot, N., and Jacquot, J. P. (2005) The plant thioredoxin system. Cell. Mol. Life Sci. 62, 24-35.

(23) Bønsager, B. C., Prætorius-Ibba, M., Nielsen, P. K., and Svensson, B. (2003) Purification and characterization of the $\beta$-trefoil fold protein barley $\alpha$-amylase/subtilisin inhibitor overexpressed in Escherichia coli. Protein Expression Purif. 30, 185-193.

(24) Shahpiri, A., Svensson, B., and Finnie, C. (2008) The NADPHdependent thioredoxin reductase/thioredoxin system in germinating barley seeds: Gene expression, protein profiles, and interactions between isoforms of thioredoxin $\mathrm{h}$ and thioredoxin reductase. Plant Physiol. 146, 789-799.

(25) Barkholt, V., and Jensen, A. L. (1989) Amino acid analysis: Determination of cysteine plus half-cystine in proteins after hydrochloric acid hydrolysis with a disulfide compound as additive. Anal. Biochem. 177, 318-322.

(26) Williams, C. H., Jr., Zanetti, G., Arscott, L. D., and McAllister, J. K. (1967) Lipoamide dehydrogenase, glutathione reductase, thioredoxin reductase, and thioredoxin. J. Biol. Chem. 242, 5226-5231.

(27) Holmgren, A. (1979) Thioredoxin catalyzes the reduction of insulin disulfides by dithiothreitol and dihydrolipoamide. J. Biol. Chem. 254, 9627-9632.

(28) Maeda, K., Hägglund, P., Björnberg, O., Winther, J. R., and Svensson, B. (2010) Kinetic and thermodynamic properties of two barley thioredoxin h isozymes, HvTrxh1 and HvTrxh2. FEBS Lett. 584, $3376-3380$

(29) Riener, C. K., Kada, G., and Gruber, H. J. (2002) Quick measurement of protein sulfhydryls with Ellman's reagent and with 4,4'-dithiodipyridine. Anal. Bioanal. Chem. 373, 266-276.

(30) Krause, G., Lundström, J., Barea, J. L., Pueyo de la Cuesta, C., and Holmgren, A. (1991) Mimicking the active site of protein disulfide-isomerase by substitution of proline 34 in Escherichia coli thioredoxin. J. Biol. Chem. 266, 9494-9500. 
(31) Åslund, F., Berndt, K. D., and Holmgren, A. (1997) Redox potentials of glutaredoxins and other thiol-disulfide oxidoreductases of the thioredoxin superfamily determined by direct protein-protein redox equilibria. J. Biol. Chem. 272, 30780-30786.

(32) Mulrooney, S. B., and Williams, C. H., Jr. (1994) Potential active-site base of thioredoxin reductase from Escherichia coli: Examination of histidine 245 and aspartate139 by site-directed mutagenesis. Biochemistry 33, 3148-3154.

(33) Bønsager, B. C., Nielsen, P. K., Abou Hachem, M., Fukuda, K., Praetorius-Ibba, M., and Svensson, B. (2005) Mutational analysis of target enzyme recognition of the $\beta$-trefoil fold barley $\alpha$-amylase/ subtilisin inhibitor. J. Biol. Chem. 280, 14855-14864.

(34) Navrot, N., Collin, V., Gualberto, J., Gelhaye, E., Hirasawa, M., Rey, P., Knaff, D. B., Issakidis, E., Jacquot, J. P., and Rouhier, N. (2006) Plant glutathione peroxidases are functional peroxiredoxins distributed in several subcellular compartments and regulated during biotic and abiotic stresses. Plant Physiol. 142, 1364-1379.

(35) Holmgren, A. (1979) Reduction of disulfides by thioredoxin. Exceptional reactivity of insulin and suggested functions of thioredoxin in mechanism of hormone action. J. Biol. Chem. 254, 9113-9119.

(36) Cheng, Z., Zhang, J., Ballou, D. P., and Williams, C. H., Jr. (2011) Reactivity of thioredoxin as a protein thiol-disulfide oxidoreductase. Chem. Rev. 111, 5768-5783.

(37) Holmgren, A., Kallis, G. B., and Nordström, B. (1981) A mutant thioredoxin from Escherichia coli tsnC 7007 that is nonfunctional as subunit of phage T7 DNA polymerase. J. Biol. Chem. 256, 3118-3124. (38) Ren, G., Stephan, D., Xu, Z., Zheng, Y., Tang, D., Harrison, R. S., Kurz, M., Jarrott, R., Shouldice, S. R., Hiniker, A., Martin, J. L., Heras, B., and Bardwell, J. C. (2009) Properties of the thioredoxin fold superfamily are modulated by a single amino acid residue. J. Biol. Chem. 284, 10150-10159.

(39) Rothwarf, D. M., and Scheraga, H. A. (1992) Equilibrium and kinetic constants for the thiol-disulfide interchange reaction between glutathione and dithiothreitol. Proc. Natl. Acad. Sci. U.S.A. 89, 79447948.

(40) Oliveira, M. A., Discola, K. F., Alves, S. V., Medrano, F. J., Guimaraes, B. G., and Netto, L. E. (2010) Insights into the specificity of thioredoxin reductase-thioredoxin interactions. A structural and functional investigation of the yeast thioredoxin system. Biochemistry 49, 3317-3326.

(41) Slaby, I., and Holmgren, A. (1979) Structure and enzymatic functions of thioredoxin refolded by complementation of two tryptic peptide fragments. Biochemistry 18, 5584-5591.

(42) Negri, A., Rodriguez-Larrea, D., Marco, E., Jimenez-Ruiz, A., Sanchez-Ruiz, J. M., and Gago, F. (2010) Protein-protein interactions at an enzyme-substrate interface: Characterization of transient reaction intermediates throughout a full catalytic cycle of Escherichia coli thioredoxin reductase. Proteins 78, 36-51.

(43) Holmgren, A., and Karlsson, G. B. (1978) Function of thioredoxin in oxidoreductions and as a subunit of phage-T7 deoxyribonucleic acid polymerase. Biochem. Soc. Trans. 6, 50-52.

(44) Nikkola, M., Gleason, F. K., and Eklund, H. (1993) Reduction of mutant phage $\mathrm{T} 4$ glutaredoxins by Escherichia coli thioredoxin reductase. J. Biol. Chem. 268, 3845-3849. 